\title{
Molecular Defects in Ferrochelatase in Patients with Protoporphyria Requiring Liver Transplantation
}

\author{
Joseph Bloomer, ${ }^{\star}$ Carol Bruzzone, ${ }^{\ddagger}$ Ling Zhu, ${ }^{\star}$ Yolanda Scarlett, ${ }^{\S}$ Scott Magness, ${ }^{\S}$ and David Brenner ${ }^{\S}$ \\ * Liver Center at The University of Alabama at Birmingham, Birmingham, Alabama 35294-0005; ${ }^{\ddagger}$ University of Minnesota, Minneapolis, \\ Minnesota 55455; and ${ }^{\S}$ University of North Carolina, Chapel Hill, North Carolina 27599-7080
}

\begin{abstract}
Protoporphyria is a genetic disorder in which a deficiency of mitochondrial ferrochelatase activity causes accumulation of protoporphyrin that produces severe liver damage in some patients. In this study, mutations of the ferrochelatase gene were examined in eight unrelated patients who had liver transplantation. RNA was prepared from liver and/ or lymphoblasts, and specific reverse transcriptase-nested polymerase chain reactions amplified and sequenced ferrochelatase cDNAs. Products shorter than normal resulted from an exon 3 deletion in three patients, exon 10 deletion in two, exon 2 deletion in one, and deletion of five nucleotides in exon 5 in one. Sequence of normal-size products revealed no other mutations. Western blot showed a reduced quantity of normal-size ferrochelatase protein in protoporphyria liver compared with normal liver (19-51\%, mean $32 \%$ of normal). Levels of the mitochondrial protein $F_{1}$ ATPase $\beta$-subunit were not decreased to a similar degree. Liver ferrochelatase activity was reduced more than could be explained by the decrease in ferrochelatase protein (4-20\%, mean $9 \%$ of normal). These results establish genetic heterogeneity in the most severe phenotype of protoporphyria. However, the gene mutations found share the property of causing a major structural alteration in the ferrochelatase protein. (J. Clin. Invest. 1998. 102:107-114.) Key words: protoporphyria $\cdot$ liver disease $\cdot$ ferrochelatase $\cdot$ molecular defects $\bullet$ exon deletions
\end{abstract}

\section{Introduction}

Protoporphyria is a genetic disorder that is characterized biochemically by the excessive accumulation and excretion of protoporphyrin, which is the immediate precursor of heme (1). The bone marrow is the predominant source of the excess protoporphyrin, with a variable contribution coming from the liver and other heme-forming tissues (2-4). The principle clinical manifestation is photosensitivity, which is caused by the

Portions of this work were presented at the Annual Meeting of Biomedicine, Washington, DC, April 1997.

Address correspondence to Joseph R. Bloomer, M.D., UAB Liver Center, 395 BHSB, 1918 University Boulevard, Birmingham, AL 35294-0005. Phone: 205-975-9699; FAX: 205-975-9393; E-mail: j_bloomer@gasmac.dom.uab.edu

Received for publication 29 July 1997 and accepted in revised form 15 April 1998.

J. Clin. Invest.

(C) The American Society for Clinical Investigation, Inc. 0021-9738/98/07/0107/08 \$2.00

Volume 102, Number 1, July 1998, 107-114

http://www.jci.org photoreactive properties of protoporphyrin circulating in dermal blood vessels and/or deposited in skin $(5,6)$. Hepatobiliary disease may also occur $(7,8)$, and some patients develop progressive liver failure that necessitates liver transplantation (9-11). The liver damage is caused by the toxic effect of protoporphyrin on liver structure and function $(12,13)$.

The enzyme abnormality that underlies protoporphyrin accumulation in protoporphyria is a deficiency of ferrochelatase activity (protoheme lyase, E.C. 4.99.1.1) (14, 15). Ferrochelatase (FC), ${ }^{1}$ the last enzyme of the heme biosynthesis pathway, is located on the matrix side of the inner mitochondrial membrane and catalyzes the insertion of ferrous iron into protoporphyrin to form heme (16). FC protein has been purified from several mammalian species, and in all has a molecular size of $40-42 \mathrm{kD}$ (17). However, radiation inactivation has demonstrated that the functional size of FC in bovine liver mitochondria is $\sim 80 \mathrm{kD}(18)$, suggesting that the enzyme exists as a homodimer in the mitochondrial membrane.

Human FC cDNA has been cloned and sequenced (19). It has an open reading frame of 1,269 base pairs, which encodes a protein of 423 amino acid residues, 54 of which are the putative mitochondrial leader sequence (Fig. 1). The FC gene contains 11 exons, has a minimum size of $45 \mathrm{~kb}$, and maps to chromosome 18 at region q21.3 $(20,21)$. There is a single gene with two polyadenylation sites that produce two mRNAs in both erythroid and nonerythroid cells (20). The deduced amino acid sequence for human FC has significant homology with FC in other mammalian species, exhibiting $88 \%$ identity to the mouse enzyme (19) and $86 \%$ to the bovine enzyme (22), although the position of the initiator methionine codon is altered in the bovine nucleotide code (22).

Recent studies have begun to define the molecular causes of deficient FC activity in patients with protoporphyria (21, 23-32), and genetic heterogeneity has been found. The study reported here focused on identifying the FC gene defects in patients with protoporphyric liver disease who required liver transplantation, in order to determine if specific mutations were associated with this severe phenotype. The study was approved by the Institutional Review Boards at The University of Alabama at Birmingham, the University of Minnesota, and the University of North Carolina.

\section{Methods}

Patient population and materials. The patient population consisted of 8 individuals, age range 13 years to 51 years, who came to liver transplantation because of advanced protoporphyric liver disease (Table I). Erythrocyte and serum protoporphyrin levels were measured fluorometrically after solvent partitioning, and liver porphyrin concentra-

1. Abbreviations used in this paper: EBVTL, EBV-transformed lymphoblasts; FC, ferrochelatase; RT-PCR, reverse transcriptasenested PCR. 


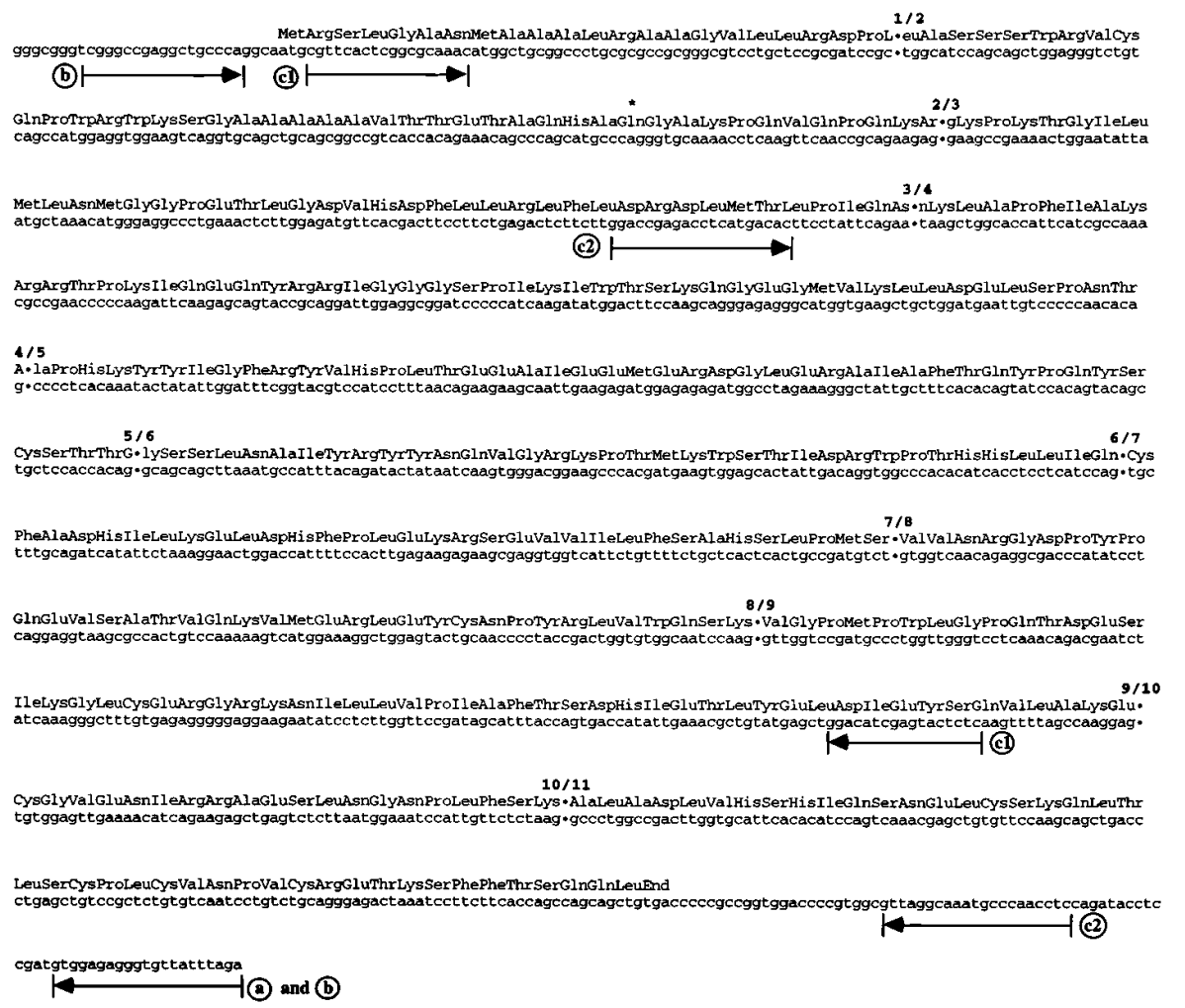

Figure 1. Structure of human FC cDNA, showing the exon sequences and boundaries, the end of the putative mitochondrial leader sequence $(*)$, and positions of the primers used in the RT-PCR to synthesize and amplify overlapping FC cDNA sequences. (a) Primer location for RT of FC mRNA; $(b)$ primer locations to synthesize and amplify the full-length coding sequence of FC cDNA; $(c 1, c 2)$ primer locations used in the nested PCR to synthesize and amplify the $5^{\prime}$ and $3^{\prime}$ portions of $\mathrm{FC}$ cDNA, respectively. tions were determined fluorometrically after extracting a portion of tissue with $0.6 \mathrm{~N}$ perchloric acid/methanol (1:1, vol/vol) (13). The erythrocyte, serum, and liver protoporphyrin concentrations in the patients were markedly increased, and the resected liver specimens showed features typical of advanced protoporphyric liver disease (7). The livers were firm in consistency and black in color. Histological examination revealed finely nodular cirrhosis, cholestasis, and the presence of birefringent protoporphyrin pigment deposits in hepatocytes, Kupffer cells, and biliary structures.

Liver tissue was obtained from each patient, except patient 8 , at the time of liver transplantation. Normal human liver was obtained from three adult organ donors whose livers were reduced in size for transplantation into children; cirrhotic liver was obtained from individuals who underwent liver transplantation because of primary biliary cirrhosis (three cases) and cryptogenic cirrhosis (one case). These specimens were obtained through the Liver Tissue Procurement and Distribution System at the University of Minnesota, directed by Dr. Harvey Sharp.

Portions of whole liver tissue were rinsed free of blood with normal saline and kept frozen at $-80^{\circ} \mathrm{C}$ until studies were carried out. A portion of whole liver was also processed by differential centrifugation to obtain a mitochondrial-enriched fraction (33). The mitochondrial pellet was suspended in $0.25 \mathrm{M}$ sucrose, $20 \mathrm{mM}$ Tris- $\mathrm{Cl}$ ( $\mathrm{pH} 7.5$ ), and aliquots were stored at $-80^{\circ} \mathrm{C}$. FC appears to be stable indefinitely in tissue that is kept at this temperature (18).

PMN and mononuclear cells were isolated from heparinized blood samples by one-step centrifugation for $30 \mathrm{~min}$ with Polymorphprep (Sigma Chemical Co., St. Louis, MO) (34). Total RNA was extracted from mononuclear cells and whole liver tissue (35), and genomic DNA was extracted from PMN and whole liver tissue (36). The peripheral blood sample was also used to establish EBV-transformed lymphoblasts (EBVTL) from five patients (37), which were used as an additional source of RNA and genomic DNA. A mononuclear cell preparation was prepared from heparinized blood samples from five healthy individuals, and EBVTL from 5 individuals with nonporphyric disorders (colon cancer, Wilms's tumor, lysencephalopathy, albinism, and asthma).
Measurement of FC activity. FC activity was measured in mitochondrial fractions prepared from the seven protoporphyric livers, three normal livers, and four cirrhotic livers based on a modification of the pyridine hemochromogen method of Porra and Jones (38). The assay mixture contained $50 \mathrm{mM}$ Tris- $\mathrm{Cl}(\mathrm{pH} 8.1), 1 \%$ sodium cholate, $5 \mathrm{mM}$ dithiothreitol, $170 \mu \mathrm{M}$ ferrous citrate, $170 \mu \mathrm{M}$ deuteroporphyrin, and 1.0-2.0 $\mathrm{mg}$ of liver mitochondrial protein in a final volume of $1 \mathrm{ml}$. The reaction was carried out anaerobically in the dark for 60 min at $37^{\circ} \mathrm{C}$ and was terminated by the addition of $33 \mathrm{mM}$ iodoacetamide in $33 \mathrm{mM}$ EDTA (final concentration). The difference spectrum between the reduced and oxidized pyridine hemochromogen was recorded using a spectrophotometer (Beckman Instruments, Fullerton, CA). The protein concentration of each mitochondrial sample was quantitated by the bicinchoninic acid method (39).

FC activity in EBVTL was measured by the formation of zinc deuteroporphyrin. EBVTL were cultured to a quantity of approximately 30 million cells, centrifuged, resuspended in $0.5 \mathrm{ml}$ of solution

\section{Table I. Patient Population}

\begin{tabular}{lccccc}
\hline & & & \multicolumn{3}{c}{ Protoporphyrin levels } \\
\cline { 5 - 6 } \multicolumn{1}{c}{ Patient } & Age & Sex & Erythrocyte & Serum & Liver \\
\hline & $y r$ & & $\mu g / d l$ & $\mu g / d l$ & $\mu g / g$ wet $w t$ \\
1 & 51 & $\mathrm{M}$ & 5276 & 160 & 3957 \\
2 & 38 & $\mathrm{~F}$ & 5131 & 144 & 5894 \\
3 & 15 & $\mathrm{M}$ & 6470 & 236 & 4599 \\
4 & 18 & $\mathrm{~F}$ & 6488 & 836 & 2606 \\
5 & 13 & $\mathrm{M}$ & 7679 & 448 & 5226 \\
6 & 14 & $\mathrm{~F}$ & 2450 & 95 & 4402 \\
7 & 36 & $\mathrm{~F}$ & 8240 & 362 & 1708 \\
8 & 27 & $\mathrm{M}$ & 6094 & 226 & - \\
Normal/control & & & $20-65$ & 0 & $0.2-1.0$ \\
& & & & &
\end{tabular}


containing $150 \mathrm{mM} \mathrm{NaCl}, 40 \mathrm{mM}$ Tris- $\mathrm{Cl}$ ( $\mathrm{pH} 7.5)$, and sonicated on ice. Sodium cholate was added to a concentration of $1 \%$, and the sample was vortexed to solubilize ferrochelatase. The sonicate from six million cells was used in each assay mixture. The same amount of boiled sonicate was used to measure nonenzymatic formation of zinc deuteroporphyrin. The sonicated mixture was added to stoppered tubes containing $0.3 \mathrm{M}$ Tris- $\mathrm{Cl}(\mathrm{pH} 7.5)$ and $1 \%$ Tween 20 , and $10 \mu \mathrm{l}$ of $5 \mathrm{mM}$ deuteroporphyrin was added. The tubes were flushed with argon for $2 \mathrm{~min}$, and the reaction was started by adding $20 \mu \mathrm{l}$ of $5 \mathrm{mM}$ zinc sulfate dissolved in 5\% ascorbic acid to achieve a reaction volume of $2 \mathrm{ml}$ (final concentrations of deuteroporphyrin and zinc were 25 and $50 \mu \mathrm{M}$, respectively). After incubation at $37^{\circ} \mathrm{C}$ for $1 \mathrm{~h}$, the reaction was stopped by adding EDTA to the reaction flask in a concentration of $50 \mu \mathrm{M}$, followed by $2 \mathrm{ml}$ of absolute ethanol. The solution was centrifuged at $12,000 \mathrm{~g}$ for $10 \mathrm{~min}$, and the supernatant was examined by fluorescence spectroscopy using a spectrofluorometer (4818 photomultiplier tube, Farrand; RCA Distributor and Special Products Division, Camden, NY), with excitation at $405 \mathrm{nM}$ and emission scanned from 550 to $700 \mathrm{nM}$. The amount of zinc deuteroporphyrin formed enzymatically was determined by comparing the fluorescence units to a zinc deuteroporphyrin standard and subtracting the amount of zinc deuteroporphyrin formed nonenzymatically.

Western blot. Anti-FC antibody was made against purified bovine FC as previously described $(18,33,40)$. Liver tissue and reference proteins were subjected to PAGE according to the method of Laemmli $(18,33,41)$. 0.1-g portions of whole liver were sonicated in $1 \%$ sodium cholate, $100 \mathrm{mM}$ Tris- $\mathrm{Cl}(\mathrm{pH} 7.4)$, and $50-\mu \mathrm{g}$ aliquots total protein were combined with an equal volume of solution that contained $125 \mathrm{mM}$ Tris-Cl (pH 6.8), 20\% glycerol, 4.6\% SDS, and $6.0 \%$ 2-mercaptoethanol and boiled for $3 \mathrm{~min}$. After $10 \%$ SDS-PAGE, the gel was electrophoretically transferred to nitrocellulose or polyvinyllidene difluoride (PVDF) membranes (Millipore Company, Bedford, MA). After blocking the membrane with $5 \%$ nonfat dry milk in $10 \mathrm{mM}$ PBS ( $\mathrm{pH} 7.4$ ), the membrane was incubated for $3 \mathrm{~h}$ with anti-FC antiserum diluted 1:500 in 5\% nonfat dry milk. The membrane was then washed and incubated for $1 \mathrm{~h}$ with goat anti-rabbit $\mathrm{IgG}$ conjugated with HRP and developed using peroxidase substrate (100 mM Tris-Cl [pH 7.4], $0.8 \mathrm{mg} / \mathrm{ml} \mathrm{3,3-diaminobenzidine,} 0.2 \mathrm{mg} / \mathrm{ml}$ nickel chloride, $0.01 \%$ hydrogen peroxide). The density of the staining was determined by video densitometry (Model GS-670; Bio-Rad Laboratories, Hercules, CA).

Western blotting was also done using antibody prepared against mouse $\mathrm{F}_{1}$-ATPase $\beta$-subunit. This was supplied by Dr. Douglas Cyr of the University of Alabama at Birmingham (42). This peptide, like $\mathrm{FC}$, is imported from the cytoplasm to the inner mitochondrial membrane.

Reverse transcriptase-nested PCR. Specific reverse transcriptasenested PCR (RT-PCR) provided template for direct sequencing of
FC cDNA (Fig. 1). This PCR method was developed to optimize the size of DNA used in amplification and sequencing. It also allowed amplification of FC mRNA in EBVTL, where FC is a rare mRNA as shown by Northern blot. Total RNA was isolated from whole liver tissue, monocytes, and EBVTL, and RT-PCR was done using up to $10 \mu \mathrm{g}$ of the RNA. The reactions were carried out in a thermal cycler (Perkin-Elmer Corp.; Norwalk, CT) under sterile mineral oil overlay, using the Gene Amp RNA PCR Kit and RNA PCR Core Kit (Perkin-Elmer Corp., Branchbury, NJ). All reactions had a negative control (no template added) run at the same time. The $\mathrm{RT}$ reaction was done in a total volume of $20 \mu \mathrm{l}$ and contained $25 \mathrm{pmol}$ of a specific primer for FC mRNA located $3^{\prime}$ to the coding region (Fig. 1). It was carried out at $37^{\circ} \mathrm{C}$ for $1 \mathrm{~h}$ and was terminated by heating at $99^{\circ} \mathrm{C}$ for 5 min to destroy the enzymes and RNA. The full-length first-cycle $\mathrm{PCR}$ reaction was then done using the entire product from the RT reaction as template. The reaction volume was $100 \mu \mathrm{l}$ and contained 50 pmol of the specific 5' primer and an additional $50 \mathrm{pmol}$ of the RT primer. There were 35 cycles of the following sequence: denaturation at $94^{\circ} \mathrm{C}$ for $10 \mathrm{~s}$, annealing of primer at $50^{\circ} \mathrm{C}$ for $10 \mathrm{~s}$, and elongation at $72^{\circ} \mathrm{C}$ for $1 \mathrm{~min}, 15 \mathrm{~s}$. Nested PCR were then carried out using $5-10 \%$ of the first cycle PCR product as template. The primer pairs were chosen to amplify 1,000 basepairs in the $5^{\prime}$ portion or $3^{\prime}$ portion of $\mathrm{FC}$ cDNA respectively (Fig. 1). The reactions were carried out in a volume of $100 \mu$ l containing $75 \mathrm{pmol}$ of each primer. They consisted of 35 cycles of the following sequence: denaturation at $94^{\circ} \mathrm{C}$ for $10 \mathrm{~s}$, annealing of primers at $50^{\circ} \mathrm{C}$ for $10 \mathrm{~s}$, and elongation at $72^{\circ} \mathrm{C}$ for $50 \mathrm{~s}$.

The PCR products were subjected to electrophoresis on $0.8 \%$ agarose gel and stained with ethidium bromide. The products of the expected 1-kb size, as well as products of smaller size were excised from the gel and purified using the Geneclean procedure (Bio 101 Inc.; La Jolla, CA). Direct sequencing was performed using an ABI 373A DNA sequencer (Applied Biosystems, Inc., Foster City, CA) with $1 \mu \mathrm{g}$ of the PCR product and 3.2 pmol of primer. Base assignment was done by ABI computer software, visually inspected, and compiled for each patient using Eugene software.

Genomic DNA sequencing. Genomic DNA was prepared from liver, polymorphonuclear leukocytes, and EBVTL. Oligonucleotides for the particular exon of interest and its flanking $5^{\prime}$ and $3^{\prime}$ regions were synthesized (Table II). PCR was carried out using GeneAmp PCR Core Reagents (Perkin-Elmer Corp.) and a GeneAmp PCR System 9600 (Perkin-Elmer Corp.). Some reactions were amplified with TaqPlus Long PCR System in low-salt reaction buffer (Stratagene Corp., La Jolla, CA). The amplified products were analyzed for appropriate size on a $1 \%$ agarose gel. The PCR product was ligated and transformed using a TA Cloning Kit (Invitrogen, Carlsbad, CA). Colonies containing PCR inserts were grown overnight in LB medium with carbenicillin and DNA extracted with a Wizard Plus Minipreps DNA Purification System (Promega Biotec; Madison, WI). DNA was sequenced with automated sequencing (ABI) and the

Table II. Primers Used to Sequence Genomic FC DNA

\begin{tabular}{llll}
$\begin{array}{l}\text { Exon and flanking } \\
\text { intron sequences }\end{array}$ & Primer type & \multicolumn{1}{c}{ Primer sequence } & \multicolumn{1}{c}{ Primer location } \\
\hline Exon 2 & Forward & 5'-GTC AGG AAT TAT GCT CTG AGG & -83 upstream to exon 2 \\
& Reverse & 5'-AGC TAT TGA AAG GAA GCC AAG & +119 downstream to exon 2 \\
Exon 3 & Forward & 5'-ACA GAT TAG AGT TTG CTG GC & -91 upstream to exon 3 \\
& Reverse & 5'-TTT AAC CAT TAC CAG ATA CGC & +95 downstream to exon 3 \\
Exon 5 & Forward & 5'-GTT GAC TCT GAG GAA TCT ATAT & -64 upstream to exon 5 \\
& Reverse & 5'-ATC TAC CTT TCC ACT GTC AGAG & +34 downstream to exon 5 \\
Exon 7 & Forward & 5'-GGA TTT TTG AGG GTT GCT & -118 upstream to exon 7 (ref. 27) \\
& Reverse & 5'-CAC TCG GCT TAG GAC ATA & +87 downstream to exon 7 (ref. 27) \\
Exon 10 & Forward & 5'-TTC CTC CCT TTT CTC AT & -26 upstream to exon 10 (ref. 28) \\
& Reverse & 5'-ACT GGA TGT GTG AAT GCA CCA AGT & Exon 11 at nucleotide position 1148-1171 (ref. 28)
\end{tabular}


exon and flanking introns were evaluated for mutations. Three to eight genomic DNA clones were sequenced to evaluate each abnormality found in FC cDNA.

Reagents. Porphyrins and porphyrin standards were obtained from Porphyrin Products, Inc. (Logan, UT). RPMI 1640, penicillin, and streptomycin used in lymphoblast culture were obtained from Gibco Life Technologies-BRL (Gaithersburg, MD). Fetal bovine serum came from Hyclone Laboratories, Inc. (Logan, UT). Goat anti-rabbit IGG conjugated with HRP was obtained from Bio-Rad Laboratories. Perchloric acid and methanol were obtained from Fisher Scientific (Pittsburgh, PA). All other reagents were from Sigma Chemical Co. (St. Louis, MO).

Statistical analysis. Results for individual groups were expressed as mean \pm SEM. Statistical comparisons between groups were done using the unpaired, two-tailed Student's $t$ test.

\section{Results}

FC gene mutations. FC cDNA amplified by RT-PCR from mononuclear cells of five healthy individuals and EBVTL of five control individuals had the same sequence as originally reported (19), with the exception that guanine replaced adenine at cDNA position 287 in all of the samples. This codes for arginine at amino acid 96 instead of glutamine, in agreement with 2 other reports $(23,31)$. It is probably the more common sequence for FC cDNA, at least in Western patients. Thus EBV transformation of lymphocytes did not cause mutations in the FC gene, which would confound the identification of genetic defects.

RT-PCR demonstrated products shorter than the expected 1,000 bases in FC cDNA prepared from liver tissue of six patients with protoporphyria (patients $1-4,6,7$ in Table I). This was also found in FC cDNA prepared from EBVTL of three patients (patients 2-4) and from EBVTL of the patient in whom liver tissue was not obtained at the time of transplantation (patient 8). The short products were visible on ethidium bromide staining of the agarose gel and could be separated from the products of normal length (Fig. 2), with the exception of patient 7 .

Sequencing showed that the short products were caused by an exon 3 deletion in patients 1, 2, and 6 (Fig. 3 and Table III). The sequence of the normal-size products generated by RTPCR in each of the patients revealed no other mutations in FC cDNA. Thus, they appear to be heterozygous for a mutation causing an exon 3 deletion. To investigate the cause of the variant $\mathrm{FC}$ cDNA, exon 3 and its flanking intron regions were amplified from genomic DNA templates and ligated into a plasmid. Clones that contained the amplified products were isolated and sequenced. In patients 1 and 2, half of the clones had the normal sequence, whereas the rest had a mutation in the consensus sequence of the highly conserved splice site (Table III), as was previously reported in a patient who was heterozygous for an exon 3 deletion (31). In patient 6 the only abnormality found was a transversion of $A$ to $C$ at position 6 in intron 3. Although this may be just a polymorphism and not a mutation that causes a splicing defect, the same transversion was not found in the remaining patients or in the healthy/control individuals. Nevertheless, confirmation that this is the splicing defect will require in vitro splicing experiments.

Sequencing of the short products generated by RT-PCR demonstrated an exon 10 deletion in patients 4 and 8 , and an exon 2 deletion in patient 3 (Table III). The sequence of the normal-size products in these patients revealed no other mutations in FC cDNA, and thus they also appear to be heterozygous for FC gene mutations. The mutation found in patient 4 on analysis of genomic DNA was an A-to-T transversion at position -3 of the donor site of intron $10(1135 \mathrm{~A} \rightarrow \mathrm{T})$, which was previously reported in a patient heterozygous for this mutation (26). Patient 8 had a deletion of this nucleotide or the next nucleotide, indicating that this part of exon 10 is critical to normal splicing.

In patient 7, the first attempt at amplification of FC cDNA by RT-PCR also demonstrated a product shorter than the expected 1,000 bases, and sequence of the short product demonstrated a deletion of exon 7. However, on the subsequent five occasions in which RT-PCR was used to amplify FC cDNA, only a product that appeared to be normal in length was found. To clarify this, the RT-PCR products were ligated with vector PCR 2.1, (Invitrogen) and plasmid inserts containing cDNAs
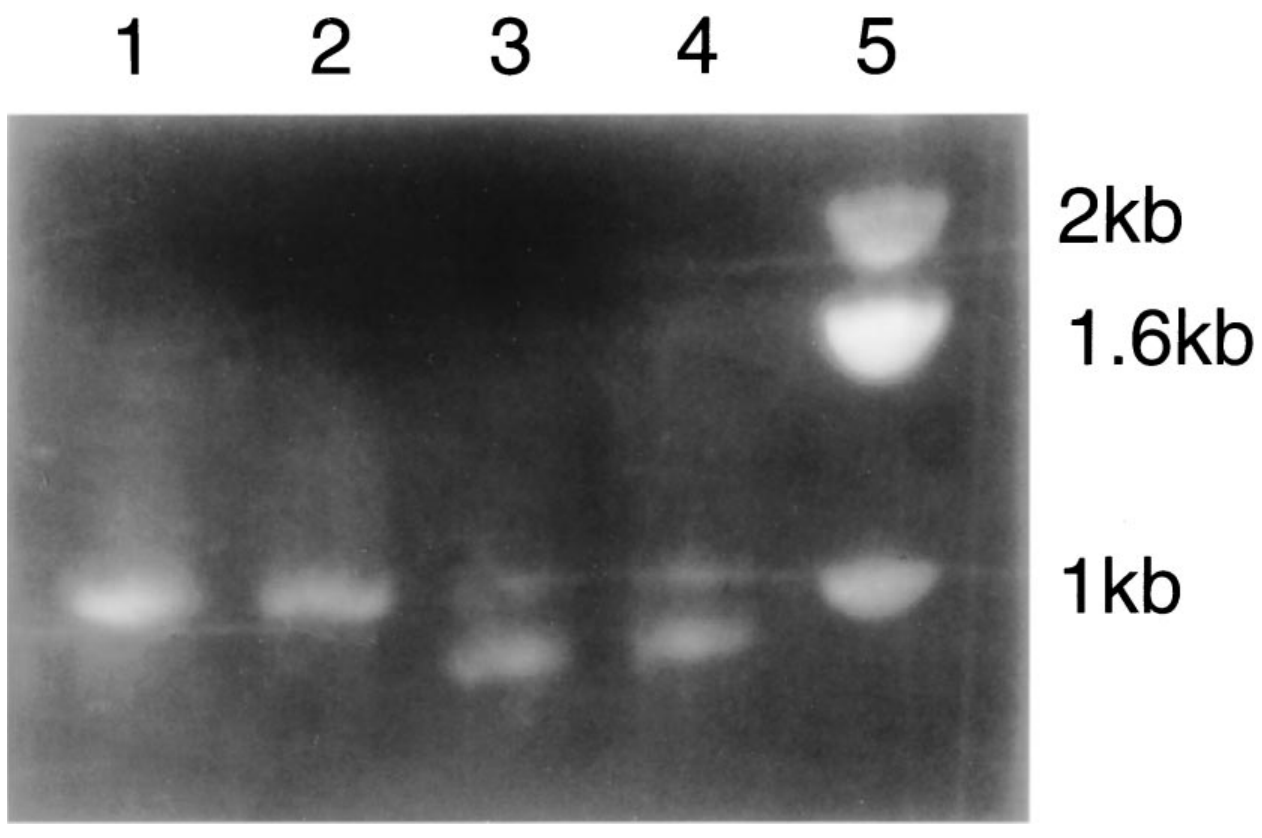

Figure 2. Ethidium bromide stain of the $5^{\prime}$ products generated from RT-PCR reactions used to amplify FC cDNA in a patient with exon 3 deletion (patient 2). (Lanes 1 and 2) Normal FC cDNA species showing the expected 1,000-base product; (lanes 3 and 4) FC cDNA species from patient who is heterozygous for exon 3 deletion, showing a short product in addition to the normallength product; (Lane 5) DNA standards. Both the normal and short products hybridized with radiolabeled FC cDNA. 
Normal Ferrochelatase cDNA
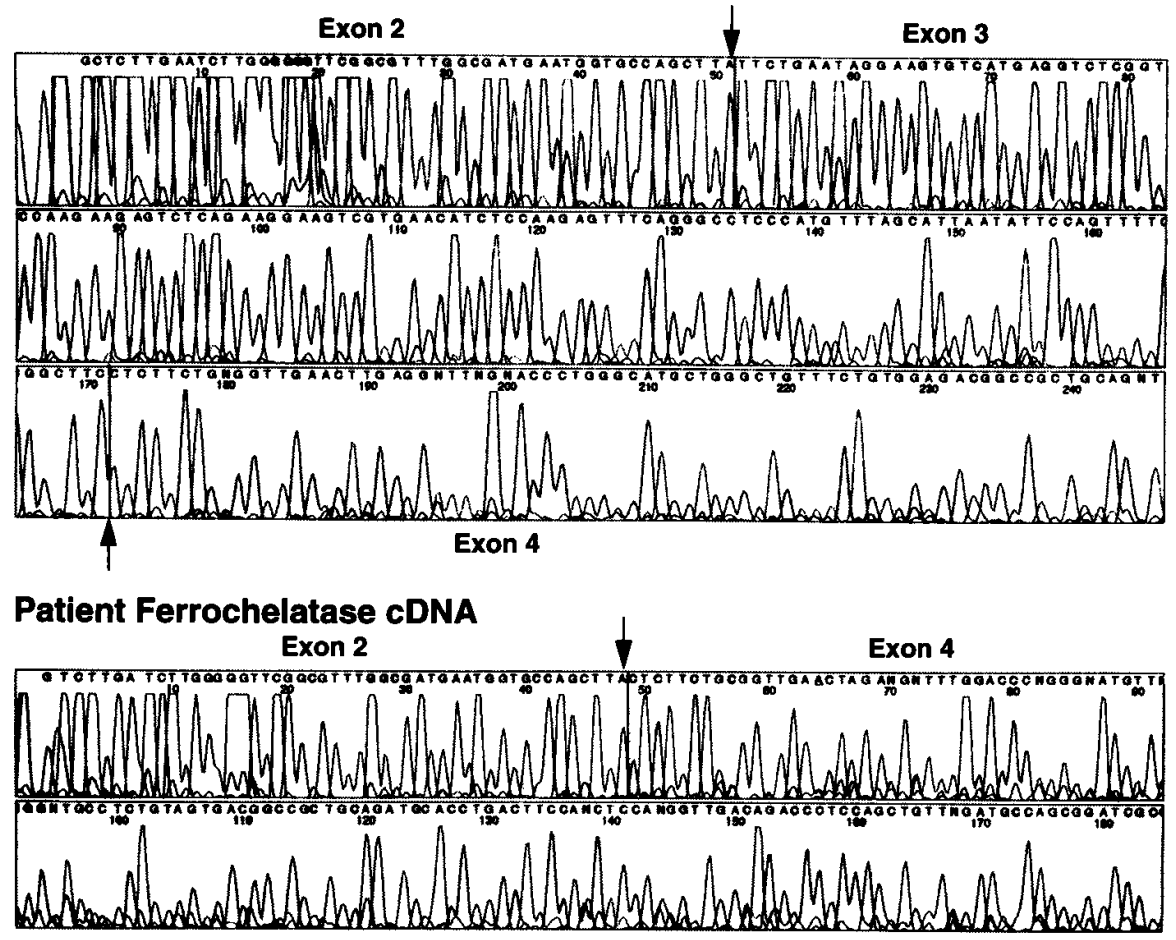

Figure 3. Sequence analysis of the short FC cDNA product in patient 2 demonstrated it to have a deletion of 120 bases (segment enclosed by arrows corresponding to exon 3 ). The sequence of the antisense strand is shown.

were sequenced. Half had the normal sequence for FC cDNA, whereas the rest had a deletion of nucleotides 580-584 in exon 5. This deletion produces a frame shift in FC mRNA, which is predicted to cause the formation of a truncated protein that is 208 amino acids long (Table III). None of the FC cDNA inserts had an exon 7 deficiency, but all contained a silent transversion in the exon 7 domain $(798 \mathrm{G} \rightarrow \mathrm{C})$. Sequencing of four clones of exon 5 and the flanking intron regions confirmed that the patient was heterozygous for a deletion of nucleotides 580584. Sequencing of eight clones of exon 7 and the flanking intron regions also confirmed the presence of the silent transversion at position 798 , but no mutation was found either in the donor splice site of intron 7 or the acceptor splice site of intron 6. The reason for the deletion of exon 7 found on one occasion by RT-PCR analysis is thus uncertain, but may reflect a lowlevel expression of abnormal mRNA, which occurred because of a spontaneous splicing abnormality rather than a true gene mutation.
In patient 5 no abnormality was found by RT-PCR in FC cDNA prepared from either liver tissue or EBVTL. Moreover, no abnormality was found when each of his exons and flanking intron regions was examined by analysis of genomic DNA, including exons 1 and 11.

Western blot analysis of hepatic FC. The effect of the mutations on FC gene expression was evaluated by Western blot of FC protein in liver tissue from seven protoporphyric patients and three normal livers. None of the patients was found to have a peptide shorter than the normal 42-kD FC protein (Fig. 4). This indicated that the mutant proteins (Table III) either were rapidly destroyed after translation, or were not reactive with the polyclonal antibody that recognized the normal protein.

The level of the normal-size $42-\mathrm{kD}$ protein in liver tissue of each of the patients, including patient 5 in whom no abnormality in FC cDNA was identified, was significantly reduced compared with that in normal liver tissue (Fig. 5). The range, as de-

Table III. FC Gene Mutations and Their Effect on FC Protein in Patients with Protoporphyric Liver Disease

\begin{tabular}{llll}
\hline Patient & \multicolumn{1}{c}{ FC cDNA sequence } & Genomic FC DNA sequence & Effect on FC protein \\
\hline 1 & Exon 3 deletion & IVS3 $+2 \mathrm{~T} \rightarrow \mathrm{G}$ & R65S and deletion of aa* 66-105 \\
2 & Exon 3 deletion & IVS3 $+2 \mathrm{~T} \rightarrow \mathrm{G}$ & R65S and deletion of aa 66-105 \\
3 & Exon 2 deletion & IVS2 $+11 \mathrm{~A} \rightarrow \mathrm{G}$ & Truncated protein 29 aa long \\
4 & Exon 10 deletion & $1135 \mathrm{~A} \rightarrow \mathrm{T}$ & Deletion of aa 360-379 \\
5 & No abnormality found & - & - \\
6 & Exon 3 deletion & IVS3 $+6 \mathrm{~A} \rightarrow \mathrm{C}$ & R65S and deletion of aa 66-105 \\
7 & $580 d e 15$ & 580 del5 & Truncated protein 208 aa long \\
8 & Exon 10 deletion & 1135AA $\rightarrow \mathrm{A}$ & Deletion of aa 360-379
\end{tabular}

*aa, amino acids. 


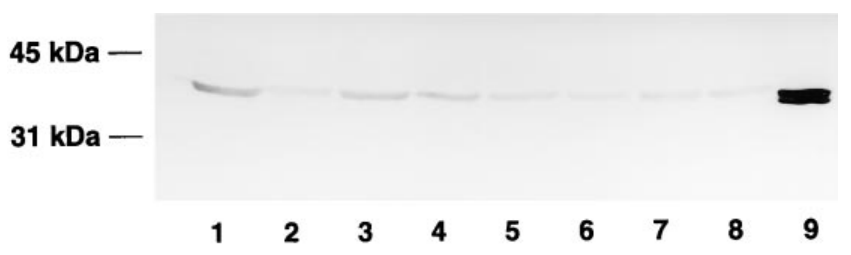

Figure 4. Western blot of normal human liver tissue (lane 1), liver tissue from seven patients (lanes 2-8) and mitochondrial extract from bovine liver (lane 9$)$. Homogenized whole liver $(400 \mu \mathrm{g})$ was loaded on each lane. First antibody was prepared against purified bovine liver FC in rabbits. A 42-kD FC protein was identified in patients and normal human liver. No shorter peptides were demonstrated.

termined by four separate determinations in each patient, was 19 to $51 \%$ of normal, with a mean of $32 \%$ for the entire group $(P<0.006$ compared to normal $)$.

The levels of $F_{1}$-ATPase $\beta$-subunit were not similarly reduced, varying from 63 to $100 \%$ of normal, with a mean of $78 \%$ for the group (Fig. 5). Thus, the decrease in the levels of normal FC protein in the livers of protoporphyric patients was due mainly to the FC gene mutations and not to a nonspecific effect of protoporphyric liver disease on mitochondrial proteins, although this may have contributed to some degree.

Hepatic FC activity. The levels of FC activity in the mitochondrial-enriched fractions of livers of patients with protoporphyria were compared with those of three normal livers and livers of four patients with other causes of cirrhosis who came to liver transplantation. The levels in the three normal livers were $14.57,16.73$, and 17.88 nanomoles deuteroheme per milligram protein per hour as determined by three separate determinations (mean level for the group, 16.39) (Table IV). The levels in the four cirrhotic livers were similar (16.61 \pm 2.76 , mean \pm SEM). In contrast, FC activity in the liver of each patient with protoporphyria was significantly reduced compared with FC activity in normal livers as determined by three or more separate measurements, varying from 4 to $20 \%$ of normal (mean 9\%, $P<0.0007$ ) (Table IV).

The protoporphyrin content of the mitochondrial fractions from the patients with protoporphyric liver disease was increased, ranging from 1.1 to $5.0 \mu \mathrm{g} / \mathrm{mg}$ protein (level in normal mitochondrial fractions was $<0.02 \mu \mathrm{g} / \mathrm{mg}$ protein). However, this contributed a concentration of only $2.0-9.0 \mu \mathrm{M}$ in the assay for FC activity, significantly less than the concentration of deuteroporphyrin that was used in the assay $(170 \mu \mathrm{M})$.

The levels of FC activity in sonicated EBVTL of five patients with protoporphyria were also significantly decreased compared with those in three normal lines $(P<0.0005)$ (Table IV). EBVTL from the patients grew normally and did not accumulate protoporphyrin under the standard culture conditions. However, when porphyrin biosynthesis was stimulated by incubating the EBVTL with $1.0 \mathrm{mM} \Delta$-aminolevulinic acid for $24 \mathrm{~h}$ in the presence of $50 \mu \mathrm{M}$ iron, the five protoporphyria lines accumulated a significantly greater amount of protoporphyrin than the three normal lines $(1376 \pm 80$ versus $617 \pm 163$ $\mathrm{pmol} / \mathrm{mg}$ protein, mean \pm SEM, $P<0.005)$.

\section{Discussion}

This study examined mutations in the FC gene in eight patients with protoporphyric liver disease who had liver trans- plantation. Different mutations were found (Table III), indicating that genetic heterogeneity exists in the most severe phenotype of protoporphyria. The mutations found share the property of causing a major structural alteration in the FC protein.

Exon deletions appear to be common in general in protoporphyria (28). However, in 29 patients without apparent liver disease in whom the FC gene defect was identified (21, 23, 24, $26-29,31,32)$, only one patient demonstrated an exon 3 deletion $(P<0.03$ by Fisher's exact test when compared with the patients in the present study). That patient was an 11-yr-old female with severe photosensitivity whose FC activity in periph-
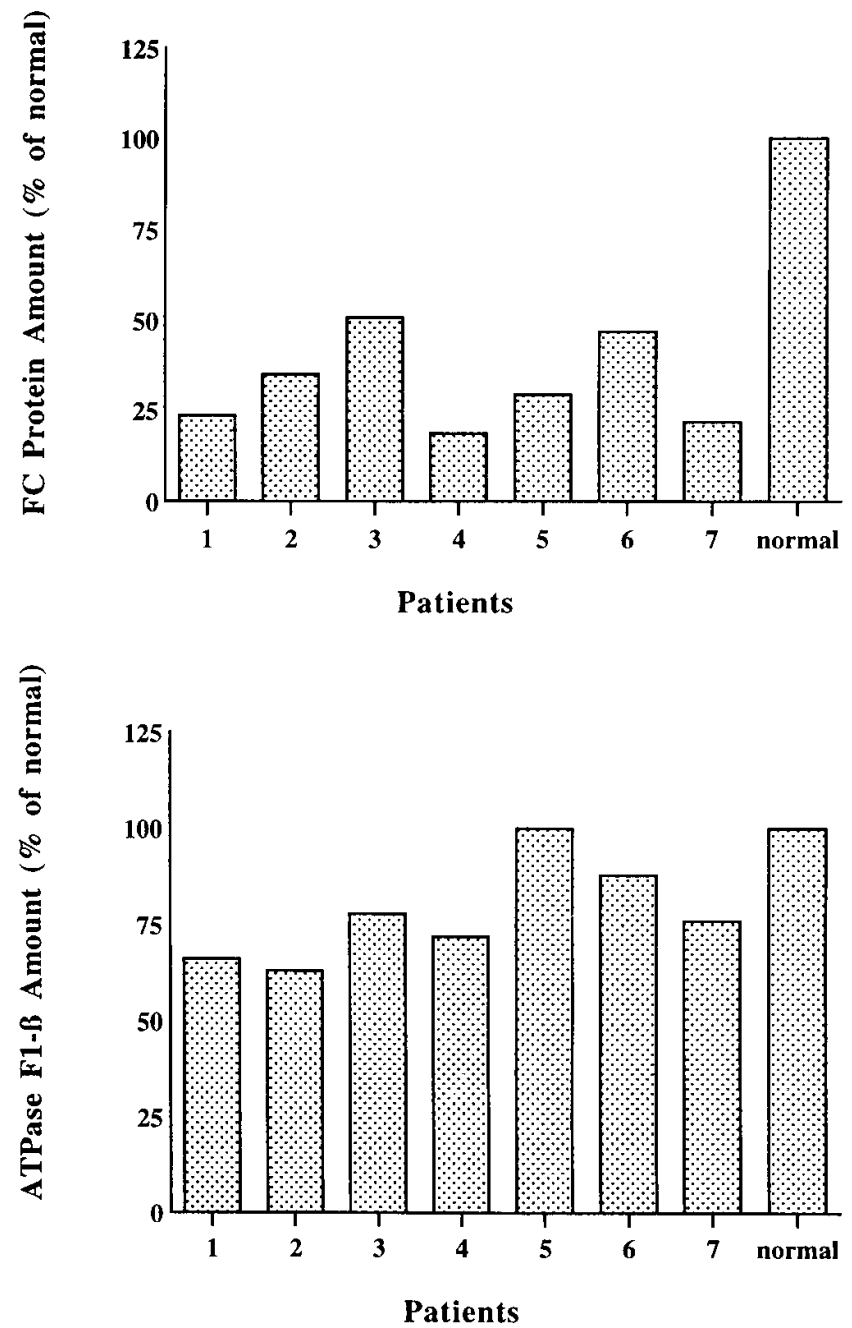

Figure 5. (Top) Quantitation of the amount of FC protein in liver tissue from seven patients and normal human liver tissue was done by Western blot. Measurement was done on $50 \mu \mathrm{g}$ total protein prepared from whole liver homogenate. The density of the staining of the FC band was determined using video densitometry. The level of $\mathrm{FC}$ in liver tissue of each patient (four determinations) was expressed as the percent of the mean level in three normal human livers. (Bottom) Quantitation of the amount of ATPase $\mathrm{F}_{1}-\beta$ protein in liver tissue from the patients was also done by Western blot. Measurement was done on $50 \mu \mathrm{g}$ total protein prepared from whole liver homogenate. The level in each patient (two determinations) was expressed as the percent of the mean level in three normal human livers. 
Table IV. FC Activity in Liver and EBVTL of Patients with Protoporphyric Liver Disease

\begin{tabular}{|c|c|c|c|c|}
\hline & \multicolumn{2}{|c|}{ Liver } & \multicolumn{2}{|l|}{ EBVTL } \\
\hline & $\begin{array}{c}\text { nmol } \\
\text { deuteroheme/ } \\
\text { mg protein } / \mathrm{h}\end{array}$ & $\begin{array}{c}\% \text { of } \\
\text { normal } \\
\text { mean }\end{array}$ & $\begin{array}{c}\mathrm{nmol} \mathrm{Zn} \\
\text { deuteroporphyrin/ } \\
\mathrm{mg} \text { protein } / \mathrm{h}\end{array}$ & $\begin{array}{c}\% \text { of } \\
\text { normal } \\
\text { mean }\end{array}$ \\
\hline Normal $(n=3)$ & $16.39 \pm 0.97$ & 100 & $14.68 \pm 0.47$ & 100 \\
\hline Patient 1 & 0.70 & 4.3 & - & - \\
\hline 2 & 0.73 & 4.5 & 0.75 & 5.1 \\
\hline 3 & 0.84 & 5.1 & 1.03 & 7.0 \\
\hline 4 & 2.18 & 13.3 & 2.16 & 14.7 \\
\hline 5 & 1.16 & 7.1 & 1.75 & 11.9 \\
\hline 6 & 3.31 & 20.2 & - & - \\
\hline 7 & 1.46 & 8.9 & - & - \\
\hline 8 & - & - & 1.23 & 8.4 \\
\hline
\end{tabular}

eral blood monocytes was only $11.7 \%$ of normal (31). Thus it will be important to follow her for signs of liver disease.

FC gene mutations have previously been identified in a limited number of patients with protoporphyric liver disease. The first case, reported by Nakahashi and co-workers (25), had a mutation at the donor site of intron 9 which resulted in the deletion of exon 9. Schneider-Yin et al. reported a patient with a point mutation $(175 \mathrm{C} \rightarrow \mathrm{T})$ that caused a stop codon that produced a truncated protein (43). Sarkany et al. described two siblings that were compound heterozygotes for an exon 10 deletion and developed liver failure in adolescence (30); and proposed that recessive inheritance may be an important factor that predisposes patients with protoporphyria to develop liver disease. However, the patients reported by Nakahashi et al. (25) and Schneider-Yin et al. (43) both had autosomal dominant inheritance (44). Moreover, no patient in the present study had evidence for recessive inheritance. Thus recessive inheritance may predispose patients with protoporphyria to develop liver disease but does not appear to be required nor to account for most of the cases.

Liver tissue was obtained from seven patients at the time of transplantation, permitting study of the effect of the mutations on FC gene expression. Proteins of shorter length than normal, which would be formed as a result of the mutations (Table III), were not detected using antibody that was made against normal bovine FC protein $(18,33)$. The antibody cross-reacts with the normal human protein because of the significant homology that exists between bovine and human FC (22). The mutant proteins may have been rapidly catabolized after translation. Alternatively, the mutations caused such alterations in the structure of the proteins that they would not react with the antibody.

Western blot analysis also showed that levels of the normal FC protein were significantly reduced, as was predicted. Some patients, in particular patient 4 , had levels much lower than the $50 \%$ of normal which would be expected from a heterozygote with one normal allele and one mutant allele. The genetic aspects of disease expression in protoporphyria have long been considered to be complex, and Went and Klasen in 1984 proposed a three-allele system based on a study of 91 families (45). Gouya et al. subsequently presented evidence for modulation of the phenotype by low expression of the normal FC al- lele in a family in which the FC gene mutation caused exon 10 skipping (32). This could explain the low level of normal FC protein in patient 4 , who also had exon 10 skipping, as well as the variability in the remainder of the patients. It is possible that liver disease also contributed to the variable level of normal FC protein, since another mitochondrial protein $\left(\mathrm{F}_{1}-\mathrm{ATP}-\right.$ ase $\beta$-subunit) was lower than normal in most of the patients.

FC activity in liver tissue was depressed even more than the level of FC protein. Due to the significant structural alterations, the mutant proteins should not have enzyme activity. However, the protein expressed by the normal allele would be expected to function normally unless modified by additional factors. The finding that EBVTL from the patients had a marked deficiency of FC activity suggests that other genetic factors are important. Protoporphyric liver damage may also be a factor. Previous studies indicated that the decrease in liver FC activity roughly correlated with the degree of liver damage in patients with protoporphyria, being most pronounced when cirrhosis was present $(15,46)$. Thus acquired factors could further inhibit the residual FC activity as the liver disease progresses. Human FC has an iron sulfur cluster that binds nitric oxide, causing inactivation of the enzyme (47), and generation of nitric oxide in damaged liver tissue might be one such factor. Another could be a change in the phospholipid fatty acyl composition of the mitochondrial membrane (48). Sequential measurements of hepatic FC activity have not been made in patients with progressive liver disease, which would help to answer this question.

The mutations also affect FC gene expression in bone marrow erythroid cells, which are the major source of excess protoporphyrin in most patients with protoporphyria (49). The abnormality in bone marrow persists after liver transplantation, and the patients continue to have elevated levels of erythrocyte protoporphyrin (11). Interpreting the cause of protoporphyrin accumulation in erythroid cells is complicated, because induction of FC and the other enzymes of the heme biosynthesis pathway occurs during erythroid differentiation $(50,51)$. The major accumulation of protoporphyrin in the developing erythrocyte occurs soon after the loss of the nucleus (52). Thus the degree of protoporphyrin accumulation in erythroid cells of patients with protoporphyria probably depends both on the effect of the gene mutation and on the pattern of induction of FC relative to the other enzymes in the heme biosynthesis pathway.

In summary, this study shows that the FC gene mutations found in patients with protoporphyria who have severe liver disease produce major structural alterations in FC protein. This is associated with a significant decrease in the level of the normal liver FC protein and in liver FC activity. Thus, the liver probably contributes to the overproduction of protoporphyrin that results in its own damage, and this may increase as liver damage progresses.

\section{Acknowledgments}

We are grateful to James Straka and Hazel Hill for help in preparing liver tissue, to Marcia Brott at the University of Minnesota for EBV transformation of lymphocytes, to Fu-Ping Chen at The University of Alabama at Birmingham for studies with the lymphoblasts, and to Mary Jenkins and Lisa Kurtz at The University of Alabama at Birmingham for assistance in sequencing FC gene mutations.

This work was supported by research grants DK-26466 (Joseph 
Bloomer), DK-47361 (David Brenner), and DK-34987 (David Brenner) from the National Institutes of Health, the Cecil J. Watson Laboratory Endowment Fund, and the Adrian Bennett Memorial Fund.

\section{References}

1. Bloomer, J.R. 1982. Protoporphyria. Semin. Liver Dis. 2:143-153.

2. Scholnick, P., H.S. Marver, and R. Schmid. 1971. Erythropoietic protoporphyria: evidence for multiple sites of excess protoporphyrin formation. $J$. Clin. Invest. 50:203-207.

3. Lamon, J.M., M.B. Poh-Fitzpatrick, A.A. Lamola, B.C. Fryckholm, M.L. Freeman, and F.H. Daeiden. 1980. Hepatic protoporphyrin production in human protoporphyria. Effects of intravenous hematin and analysis of erythrocyte protoporphyrin distribution. Gastroenterology. 79:115-125.

4. Poh-Fitzpatrick, M.B. 1985. Protoporphyrin metabolic balance in human protoporphyria. Gastroenterology. 88:1239-1242.

5. Goldstein, B.D., and L.C. Harber. 1972. Erythropoietic protoporphyria: lipid peroxidation and red cell membrane damage associated with photohemolysis. J. Clin. Invest. 51:892-902.

6. Gigli, I., A.A. Schotharst, N.A. Soter, and M.A. Pathak. 1980. Erythropoietic protoporphyria. Photoactivation of the complement system. J. Clin. Invest. $66: 517-520$.

7. Bloomer, J.R., M.J. Phillips, D.L. Davidson, and G. Klatskin. 1975. Hepatic disease in erythropoietic protoporphyria. Am. J. Med. 58:869-882.

8. Doss, M.O., and M.F. Frank. 1989. Hepatobiliary implications and complications in protoporphyria: a 20-year study. Clin. Biochem. 22:223-229.

9. Polson, R.J., C.K. Lim, K. Rolles, R.Y. Caine, and R. Williams. 1988. The effect of liver transplantation in a 13-year old boy with erythropoietic protoporphyria. Transplantation. 46:386-389.

10. Samuel, D., B. Boboc, J. Bernau, H. Bismuth, and J. Benhamou. 1988. Liver transplantation for protoporphyria. Evidence for the predominant role of the erythropoietic tissue in protoporphyrin overproduction. Gastroenterology. 95:816-819.

11. Bloomer, J.R., J.M. Rank, W.D. Payne, D.C. Snover, H.L. Sharp, R.J. Zwiener, and R.L. Carithers. 1996. Follow-up after liver transplantation for protoporphyric liver disease. Liver Transplant. Surg. 2:269-275.

12. Avner, D.L., R.G. Lee, and M.M. Berenson. 1981. Protoporphyrininduced cholestasis in the isolated in situ perfused rat liver. J. Clin. Invest. 67:385394.

13. Morton, K.O., F. Schneider, M.K. Weimer, J.G. Straka, and J.R. Bloomer. 1988. Hepatic and bile porphyrins in patients with protoporphyria and liver failure. Gastroenterology. 94:1488-1492.

14. Bottomley, S.S., M. Tanaka, and M.A. Everett. 1975. Diminished erythroid ferrochelatase activity in protoporphyria. J. Lab. Clin. Med. 86:126-131.

15. Bonkowsky, H.L., J.R. Bloomer, M.J. Mahoney, and P.S. Ebert. 1975. Heme synthetase deficiency in human protoporphyria. Demonstration of the defect in liver and cultured skin fibroblasts. J. Clin. Invest. 56:1139-1148.

16. Harbin B.M., and H.A. Dailey. 1985. Orientation of ferrochelatase in bovine liver mitochondria. Biochemistry. 24:366-370.

17. Dailey, H.A., J.E. Fleming, and B.M. Harbin. 1986. Purification and characterization of mammalian and chicken ferrochelatase. Methods Enzymol. 123:401-408

18. Straka, J.G., J.R. Bloomer, and E.S. Kempner. 1991. The functional size of ferrochelatase determined in situ by radiation inactivation. J. Biol. Chem. 266:24637-24641.

19. Nakahashi, Y., S. Taketani, M. Okuda, K. Inoue, and R. Tokunaga. 1990. Molecular cloning and sequence analysis of cDNA encoding human ferrochelatase. Biochem. Biophys. Res. Commun. 173:748-755.

20. Taketani, S., J. Inazawa, Y. Nakahashi, T. Abe, and R. Tokunaga. 1992. Structure of the human ferrochelatase gene. Eur. J. Biochem. 205:217-222

21. Brenner, D.A., J.M. Didier, F. Frasier, S.R. Christensen, G.A. Evans, and H.A. Dailey. 1992. A molecular defect in human protoporphyria. Am. J. Hum. Genet. 50:1203-1210.

22. Shibuya, H., D. Nonneman, M. Tamassia, O.L. Allphin, and G.S. Johnson. 1995. The coding sequence of the bovine ferrochelatase gene. Biochim. Biophys. Acta. 1231:117-120.

23. Lamoril, J., S. Boulechfar, H. deVerneuil, B. Grandchamp, Y. Nordmann, and J.C. Deybach. 1991. Human erythropoietic porphyria: two point mutations in the ferrochelatase gene. Biochem. Biophys. Res. Commun. 181:594-599.

24. Nakahashi, Y., H. Fujita, S. Taketani, N. Ishida, A. Kappas, and S. Sassa. 1992. The molecular defect of ferrochelatase in a patient with erythropoietic protoporphyria. Proc. Natl. Acad. Sci. USA. 89:281-285.

25. Nakahashi, Y., H. Miyazaki, Y. Kadota, Y. Naitoh, K. Inoue, M. Yamamoto, N. Hayashi, and S. Taketani. 1993. Molecular defect in human erythropoietic protoporphyria with fatal liver failure. Hum. Genet. 91:303-306.

26. Wang, X., M. Poh-Fitzpatrick, D. Carriero, L. Ostasiewicz, T. Chen, S. Taketani, and S. Piomelli. 1993. A novel mutation in erythropoietic protoporphyria: an aberrant ferrochelatase mRNA caused by exon skipping during
RNA splicing. Biochim. Biophys. Acta. 1181:198-200.

27. Nakahashi, Y., H. Miyazaki, Y. Kadota, Y. Naitoh, K. Inoue, M. Yamamoto, N. Hayashi, and S. Taketani. 1993. Human erythropoietic protoporphyria: identification of a mutation at the splice donor site of intron 7 causing exon 7 skipping of the ferrochelatase gene. Hum. Mol. Genet. 2:1069-1070.

28. Wang, X., M. Poh-Fitzpatrick, S. Taketani, T. Chen, and S. Piomelli. 1994. Screening for ferrochelatase mutations: molecular heterogeneity of erythropoietic protoporphyria. Biochim. Biophys. Acta. 1225:187-190.

29. Magness, S.T., A. Tugores, S.R. Christensen, C. Wagner-Mcpherson, G.A. Evans, E.W. Naylor, and D.A. Brenner. 1994. Deletion of the ferrochelatase gene in a patient with protoporphyria. Hum. Mol. Genet. 3:1695-1697.

30. Sarkany, R.P.E., G.J.M.A. Alexander, and T.M. Cox. 1994. Recessive inheritance of erythropoietic protoporphyria with liver failure. Lancet. 343: 1394-1396.

31. Sarkany, R.P.E., D.M. Whitcombe, and T.M. Cox. 1994. Molecular characterization of a ferrochelatase gene defect causing anomalous RNA splicing in erythropoietic protoporphyria. J. Invest. Dermatol. 102:481-484.

32. Gouya, L., J.C. Deybach, J. Lamoril, V. Da Silva, C. Beaumont, B. Grandchamp, and Y. Nordmann. 1996. Modulation of the phenotype in dominant erythropoietic protoporphyria by a low expression of the normal ferrochelatase allele. Am. J. Hum. Genet. 58:292-299.

33. Bloomer, J.R., H.D. Hill, K.O. Morton, L.A. Anderson-Burnham, and J.G. Straka. 1986. The enzyme defect in bovine protoporphyria. Studies with purified ferrochelatase. J. Biol. Chem. 262:667-671.

34. Ferrante, A., and Y.H. Thong. 1980. Optimal conditions for simultaneous purification of mononuclear and polymorphonuclear leukocytes from human peripheral blood by the Ficoll-Hypaque method. J. Immunol. Methods. 36:109-117.

35. Chomczyski, P., and N. Sacchi. 1987. Single-step method of RNA isolation by acid guanidinium thiocyanate-phenol-chloroform extraction. Anal. Biochem. 162:156-159.

36. Chapdelaire, P., S. Delehaye, E. Gauthier, R.R. Tremblay, and J.Y. Dupe. 1993. A one-hour procedure for the preparation of genomic DNA from frozen tissue. Bio. Techniques. 14:163-164.

37. Lostonlen, D., G. Lenoir, and J.C. Kaplan. 1981. NADH-cytochrome bg reductase activity in lymphoid cell lines. Expression of the defect in EpsteinBarr virus transformed lymphoblastoid cell lines from patients with recessive congenital nethemoglobinemia. J. Clin. Invest. 68:279-285.

38. Porra, R.J., and O.T.G. Jones. 1963. Studies on ferrochelatase, I. assay and properties of ferrochelatase from a pig-liver mitochondrial extract. Biochem. J. 87:181-185.

39. Smith, P.K., R.I. Krohn, G.T. Hermanson, A.K. Mallia, F.H. Gartner, M.D. Provenzano, E.K. Fujimoto, N.M. Goeke, B.J. Olson, and D.C. Klenk 1985. Measurement of protein using bicinchoninic acid. Anal. Biochem. 150:76-85.

40. Hurn, B.A.L., and S.M. Chantler. 1980. Production of reagent antibodies. Methods Enzymol. 70:104-142.

41. Laemmli, U.K. 1970. Cleavage of structural proteins during the assembly of the head of bacteriophage T4. Nature. 227:680-685.

42. Cyr, D.M., and M.G. Douglas. 1991. Early events in the transport of proteins into mitochondria. J. Biol. Chem. 266:21700-21708.

43. Schneider-Yin, X., B. Schäfer, P. Möhr, and E.I. Minder. 1994. Molecular defects in erythropoietic protoporphyria with terminal liver failure. Hum. Genet. 93:711-713.

44. Schneider-Yin, X., S. Taketani, B. Schäfer, and E.I. Minder. 1994. Recessive inheritance of erythropoietic protoporphyria with liver failure. Lancet. 344:337.

45. Went, L.N., and E.C. Klasen. 1984. Genetic aspects of erythropoietic protoporphyria. Ann. Hum. Genet. 48:105-117.

46. Bloomer, J.R. 1979. Pathogenesis and therapy of liver disease in protoporphyria. Yale J. Biol. Med. 52:39-48.

47. Sellers, V.M., M.K. Johnson, and H.A. Dailey. 1996. Function of the $(2 \mathrm{Fe}-2 \mathrm{~S})$ cluster in mammalian ferrochelatase: a possible role as a nitric oxide sensor. Biochemistry. 35:2699-2704.

48. Kools, A.M., J.G. Straka, H.D. Hill, D.I. Whitmer, R.T. Holman, and J.R. Bloomer. 1989. Modulation of hepatic ferrochelatase activity by dietary manipulation of mitochondrial phospholipid fatty acyl groups. Hepatology. 9: 557-561.

49. Poh-Fitzpatrick, M.B. 1985. Protoporphyrin metabolic balance in human protoporphyria. Gastroenterology. 88:1239-1242.

50. Fujita, H., M. Yamamoto, T. Yamagami, N. Hayashi, T.R. Bishop, H. De Verneuil, T. Yoshinagu, S. Shibahara, R. Morimoto, and S. Sassa. 1991. Sequential activation of genes for heme pathway enzymes during erythroid differentiation of mouse Friend virus-transformed erythroleukemia cells. 1991. Biochim. Biophys. Acta. 1090:311-316.

51. Lake-Bullock, H., and H.A. Dailey. 1993. Biphasic ordered induction of heme synthesis in differentiating murine erythroleukemia cells: role of erythroid 5-aminolevulinate synthase. Mol. Cell. Biol. 13:7122-7132.

52. Clark, K.G.A., and D.C. Nicholson. 1971. Erythrocyte protoporphyrin and iron uptake in erythropoietic protoporphyria. Clin. Sci. 41:363-370. 